\title{
A rare presentation of Ectopic Cushing Syndrome in a patient with small cell lung cancer
}

\author{
Sakthiraj $\mathrm{N}^{1}$, Janson $J^{2}$, Ghetheeswaran $\mathrm{S}^{3}$
}

\section{Summary}

Ectopic Cushing's syndrome (ECS) is a rare para neoplastic syndrome that occurs in patients with small cell lung cancer (SCLC). Because of the aggressive nature of the syndrome and its atypical features, ECS in small-cell lung cancer is difficult to diagnose and has a poor prognosis. We report a case of a 53-year-old male patient who presented with severe proximal muscle weakness in all ${ }^{4}$ limbs, and loss of appetite. He had no chest symptoms. The patient was eventually diagnosed with stage IV primary small-cell lung cancer with ECS and survived only one week following diagnosis. We have conducted a review of relevant published articles.

\section{Background}

Ectopic Cushing's syndrome (ECS) is a rare paraneoplastic syndrome that occurs with small cell lung cancer (SCLC) in around $1-5 \%$ of cases.

Small-cell lung cancer patients with ECS have a very poor prognosis, without treatment with a life expectancy of approximately 3.5 months for limited-stage disease and 6 weeks for extensive-stage disease; with treatment it increases to 14-18 months for limited-stage disease and 9-12 months for extensive-stage disease. Therefore, the early diagnosis of ECS in small cell cancer patients and the effective control of hypercorticolism may achieve longer survival. As illustrated in this case report in some patients with small cell cancer with ECS, typical chest symptoms may be absent. Rarely, typical signs and symptoms of Cushing's syndrome may not be present such as rapid weight gain, central obesity, fat pads on the back of the neck and on the face, thinning of the skin and striae. In such cases the secretion from malignant tumour cells results in a metabolic condition of excessive mineralocorticoid action with predominant muscle weakness due to hypokalaemic alkalosis.

\section{Case presentation}

A 53 years old male farmer, a non-smoker with a known Type 2 diabetes mellitus patient on regular follow up, presented with one month history of difficulty in getting up, rapidly worsening proximal muscles weakness in lower limbs which were not accompanied with fever, muscle or bone pain. He had recently lost his appetite without any significant loss in body weight and also developed increased thirst and claimed that he had passed more than 4.5 litre of urine per day for the last few days.

\footnotetext{
${ }^{1}$ Registrar in medicine Teaching Hospital Jaffna ,Sri Lanka.

${ }^{2}$ Senior registrar in medicine Teaching Hospital Jaffna, Sri Lanka.

${ }^{3}$ Consultant Physician Teaching Hospital Jaffna, Sri Lanka.
} 
He denied of having had cough, haemoptysis or pleuretic pain. He had not experienced any bowel symptoms, cold intolerance, and palpitation or increased sweating.

On examination at the time of presentation, there was no central obesity except for some facial puffiness. He appeared pale with mild icterus. He had no acne, striae, skin rashes or abnormal pigmentation. There was no clubbing, muscle tenderness or lymphadenopathy.

Examination of the cardiovascular system revealed a pulse rate of $110 \mathrm{bpm}$ which was regular, but his blood pressure was elevated at 220/140 mmHg in both arms. There were no heaves, thrills or murmurs on cardiovascular examination. His JVP was normal..Examination of his chest and abdomen was normal. Nervous System examination revealed symmetrical proximal muscle weakness in all $^{4}$ limbs; with normal tone, reflex and sensation.

The patient had been investigated one month previously for severe back pain following heavy exertion and clinical examination then was unremarkable; investigations were normal including x-ray and CT scan of the lumbosacral spine.

\section{Investigations}

The patient was found to be anaemic with an $\mathrm{Hb}$ of $11 \mathrm{~g} / \mathrm{dl}$ and also had a low level of serum potassium of $2.9 \mathrm{~mm} \mathrm{l} / \mathrm{l}$, hypokalaemic alkalosis in arterial blood gas analysis with abnormal liver function tests (ALT - $121 \mathrm{u} / \mathrm{l}$, AST - 216 u/l, ALP - 87 u/l, Albumin $23 \mathrm{~g} / \mathrm{l}$, total bilirubin $32 \mathrm{micromols} / \mathrm{l}$ and direct Bilirubin $22 \mathrm{micromol} / \mathrm{l}$ ). His serum calcium was $2.82 \mathrm{~m}$. $\mathrm{mol} / \mathrm{l}$. On low dose overnight dexamethasone suppression, his baseline 9 am serum cortisol was not suppressed, remained elevated at 926 $\mathrm{nmol} / \mathrm{l}$; and persistently high at $846 \mathrm{nmol} / \mathrm{l}$ following the high dose dexamethasone suppression.

CT scan of the thorax revealed an apical mass in the right upper lobe of the lung with enlarged mediastinal lymphnodes. CT scan of the abdomen revealed a mildly enlarged liver and bone metastases. Histology done on liver lesions confirmed metastatic carcinoma mostly from small cell lung cancer origin.

\section{Treatment and outcome}

The patient was immediately commenced on IV fluid $4 \mathrm{l}$ /day, Iv furosemide $40 \mathrm{mg}$ bd, Ketoconazole 200 mg tds, Tramadol 50 mg bd and transferred to oncology unit. Chemotherapy was commenced but the patient died one week later.

\section{Discussion}

Ectopic Cushing's syndrome, secondary to lung cancer, is rare and was first recognized in 1928 in a patient with small cell carcinoma of the lung ${ }^{1}$. Initially the syndrome was associated with small cell lung cancer, but it now includes carcinoid tumours especially of the lungs, thymus, and gastrointestinal tract, islet cell tumours, phaeochromocytomas, and medullary thyroid carcinomas ${ }^{2}$. Clinical Cushing syndrome secondary to ectopic ACTH production is uncommon, occurring in $3.2 \%$ $4.5 \%$ of SCLC patients ${ }^{3}$. ECS in SCLC does not usually exhibit the classic signs of $\mathrm{CS}^{4}$ and the varied clinical presentation makes diagnosis difficult wide variety of clinical manifestations make it more difficult to diagnose ECS in SCLC, especially at early clinical stages. 
A retrospective study ${ }^{5}$ has revealed that the median survival of SCLC patients with ECS is from 3.5 to 5.5 months confirming that the presence of EAS is a poor prognostic factor. Patients with ectopic ACTH production have high ACTH levels (>20 ng/L) and cortisol levels fail to be suppressed with high doses of dexamethasone ( $8 \mathrm{mg} /$ day) and demonstrate absent pituitary adrenal responses to corticotropin-releasing hormone ${ }^{6}$.

Management of patients with ectopic ACTH requires control of the hyper-cortisolaemia as soon as the diagnosis is established and ketoconazole and metyrapone have good evidence for their efficacy and safety ${ }^{7,8}$.

Ectopic ACTH-secreting tumours is challenging for differential diagnoses and therefore require careful clinical, biochemical, radiological, and pathological investigation and are best managed in a multidisciplinary setting.

This case report and review suggests that SCLC patients with ECS have a poor prognosis and the diagnosis of the condition can be challenging but it is important to exclude ECS in SCLS patients presenting with atypical signs and symptoms as this would lead to early detection and effective treatment of the underlying cancer.

\section{Learning points/take home messages}

- Ectopic Cushing Syndrome in SCLC patients is a rare condition with a poor prognosis.

- Ectopic Cushing Syndrome in SLCS patients does not usually exhibit typical signs and symptoms of Cushings disease.
- Early diagnosis and prompt and effective treatment could prolong survival of the patient.

\section{Reference:}

1. Brown W H, "A case of pluriglandular syndrome: "diabetes of bearded women",' The Lancet, vol. 212, no. 5490, pp. 1022-1023, 1928.

2. Beuschlein, Hammer G D, "Ectopic proopiomelanocortin syndrome," Endocrinology and Metabolism Clinics of North America, vol. 31, no. 1, pp. 191-234, 2002.

3. Shepherd FA, Laskey J, Evans WK, Goss PE, et al. Cushing's syndrome associated with ectopic corticotropin production and small-cell lung cancer. J ClinOncol. 1992;10:21-27.

4. Imura H, Matsukura S, Yamamoto H, Hirata Y, NakaiY.Studies on ectopic ACTH-producing tumors. II. Clinical andbiochemical features of 30 cases. Cancer 1975; 35: 1430-7.

5. Lokich JJ. The frequency and clinical biology of the ectopic hormone syndromes of small cell carcinoma. Cancer. 1982;50:2111-2114

6. Howlett T A. , Drury P L, Perry L, et al, "Diagnosis and management of ACTH-dependent Cushing's syndrome: comparison of the features in ectopic and pituitary ACTH production," Clinical Endocrinology, vol. 24, pp. 699-713, 1986I. Ilias, D.

7. Tabarin A, Navarranne A, Guerin J, et al, "Use of ketoconazole in the treatment of Cushing's disease and ectopic ACTH syndrome," Clinical Endocrinology, vol. 34, no. 1, pp. 63-69, 1991. View at Google Scholar. View at Scopus

8. Engelhardt D, Weber M M, "Therapy of Cushing's syndrome with steroid biosynthesis inhibitors," Journal of Steroid Biochemistry and Molecular Biology, vol. 49, no. 4-6, pp. 261-267, 1994. 